\title{
PERSONA Y PERSONAJE EN LA ESCRITURA MEMORIALÍSTICA DE TERENCI MOIX
}

\author{
Thomas Fone \\ Universidad de Dúala (Camerún)
}

\section{RESUMEN}

El objeto de este trabajo es analizar las figuras narrativas de las que va a servirse Terenci Moix para construir el sujeto textual que exhibirá en sus memorias. Importa el significado de dicha selección en tanto que dichas fórmulas colaboran a crear una identidad literaria que muestra la volubilidad personal tributaria de valor de la libertad, la emancipación y la necesidad de transformarse para influir en el entorno cultural. Los distintos modos de la enunciación autobiográfica pasan de ser un juego estético-intelectual a convertirse en el instrumento que permita al sujeto autobiográfico desdoblarse, subjetivarse y objetivarse con el fin de descubrir las caras del yo, revelando las seńas de identidad y angustias existenciales que sustancian una personalidad.

PALABRAS ClAVE: memorias, figuras narrativas, autorrepresentación, pacto autobiográfico, Terenci Moix.

\author{
PERSONA AND CHARACTER \\ IN TERENCI MOIX'S MEMOIR WRITINGS
}

\section{Abstract}

The aim of this work is to analyze the narrative figures that Terenci Moix uses to construct the textual subject that appears in his memoirs. The meaning of such selection matters insofar as these formulas collaborate to create a literary identity that shows the personal tributary volubility of the value of freedom, emancipation and the need to transform oneself to influence the cultural environment. The different modes of autobiographical enunciation go from being an aesthetic-intellectual game to becoming the instrument that allows the autobiographical subject to unfold, subjectify and objectify himself in order to discover the faces of the self, revealing the signs of identity and existential anguish of a personality. KEYWORDs: Memoirs, narrative figures, self-representation, autobiographical pact, Terenci Moix. 
Por ser la categoría del discurso que integra y determina todas las demás, la crítica literaria ${ }^{1}$ incide en la prioridad de definir el tipo de narrador, a la hora de analizar el relato, puesto que se trata de la instancia que dicta los principios organizativos y reguladores de la información. Y si para llegar al significado narrativo es necesario siempre dar cuenta de sus rasgos y configuración, tanto más imprescindible se hace en el caso de la literatura personal, dada la inevitable identificación del yo que escribe y el yo narrador. Como todo relato, el autorreferencial tiene un resultado informativo y significativo dependiente de las elecciones que hace el narrador en el desarrollo de su enunciado, pero además es precisamente en la tensión que establece el texto entre lo vivido y su verbalización donde radica la especificidad de la escritura del yo, cuyos valores pueden ser medidos por los índices de la distancia y la perspectiva, aspectos que configuran la voz narrativa y que van a ser reveladores del sujeto estético trazado en los relatos de vida (Molero de la Iglesia 2000: 73). Tanto escritores como lectores relacionan la narrativa autobiográfica y memorialística con la primera persona, puesto que quien habla es forzosamente un yo y el pacto autobiográfico conlleva la responsabilidad del hablante respecto a lo narrado (May 1982: 80); por eso, de la primera persona del singular resalta Ciplijauskaiti su capacidad "para lograr la impresión de una estructura viva» mediante la que ofrecer la mejor imagen de sí mismo, favoreciendo la indagación psicológica (Puertas Moya 2004: 119). Sin embargo, afectados por la óptica retrospectiva, el insospechado funcionamiento de la memoria y los decisivos factores de temporalización y modalización seleccionados por el narrador, en el momento de exponer los hechos, el ejercicio de representación que supone dar forma verbal a lo vivido depende tanto de intereses estéticos como de autorrepresentación. En tal sentido, el enunciado narrativo dispone de recursos discursivos con los que construir el relato de la trayectoria vital, de acuerdo con el proyecto que el autobiógrafo tenga para la representación de la propia imagen. Las llamadas figuras de la enunciación encierran los significados que el escritor personal concede a la evolución de su vida y su personalidad, permitiéndole estetizar una imagen en la que tenga cabida lo que ha vivido y lo que desea vivir, lo sońado, lo deseado, lo fantaseado, lo imaginado y lo inventado. Tales posibilidades del yo escrito responden a lo que Gusdorf (1991a: 8) denomina les écritures du moi.

En la empresa literaria de objetivar la visión sobre sí mismo y exhibir la propia personalidad, Terenci Moix recurre en sus memorias ${ }^{2}$ a los recursos narrativos que le van a permitir acercar o alejar, enfocar o deformar ese sujeto literario que pretende revelarse a través de los juegos de desdoblamiento, multiplicidad e impostura, utilizando la primera persona, la tercera persona, la forma impersonal y la pri-

${ }^{1}$ Entre dichos teóricos, Bal (1998) y, sobre todo, Pozuelo Yvancos (1994), que recoge la aportación de los estudios llevados a cabo por críticos anglosajones, haciendo hincapié en la de los franceses, tales como Todorov y Genette.

2 Aunque sus memorias, El cine de los sábados, El beso de Peter Pan y Extraño en el paraíso, fueron publicadas respectivamente en 1990, 1993 y 1998, en el presente trabajo he utilizado para las tres entregas la edición de 1998. 
mera persona del plural, para ejecutar actos como los de autorretratarse, exponer su sexualidad justificándola o asumiéndola públicamente, dar significado a sus viajes, exhibir una abundante y fructífera interacción con todos los órdenes de la cultura y reflejar la propia conciencia en sus actitudes sociales, etc.; son móviles de sus memorias que quien se autoescribe presenta como compromiso personal. En el proyecto de reconstruir el personaje en su momento histórico, Moix favorecerá el uso de la primera persona, con el fin de llevar a cabo una revisión de la memoria que le ayude a dar sentido a la existencia. Dicha figura de la enunciación está presente al principio de cada secuencia de sus tres obras y se activa de manera constante en las mismas, con un gran efecto de reafirmación evidente en aserciones de tipo personal. La primera persona asume la responsabilidad de la función figuradora del sujeto, tanto en el relato de la peripecia personal como en el análisis de dicha trayectoria vital. La coincidencia del yo narrador y el yo personaje organiza el relato de la niñez y su diagnóstico de la infancia feliz, en complacencia dicha voz narradora del hombre maduro con un sujeto que tempranamente rompe con la obediencia e inocencia infantil, para rebelarse contra un entorno social dominado por los educadores religiosos.

Precisamente será la narrativa del yo la que solape la incoherencia que supone un personaje intervenido por la voz de la conciencia adulta, como sucede con la atribución al niño de esa capacidad para aceptar y asumir, con una normalidad madura, las continuas broncas familiares y la asiduidad de su padre a los prostíbulos. En realidad, no es más que un solapamiento de la conciencia adulta, posible en narrativa aplicando la perspectiva de la voz narradora, ya que dichas vivencias sirven para justificar un carácter provocativo y trasgresor, cuya representación en el texto tiene como objetivo mostrar la diferencia del $\mathrm{yo}^{3}$. Así pues, la primera persona es la que domina el enunciado memorialístico en este autor, por la búsqueda de efectos emocionales que convierta en cómplice a un lector que acude a sus escritos buscando contenidos agresivos con respecto a los códigos sociales, pero también anecdóticos, dada la condición pública del escritor. Y en efecto, su relato está lleno de sucesos dirigidos a afianzar dicha imagen, presentándose desde la temprana edad como un niño predestinado al mundo del espectáculo, a este fin sirve el relato de episodios como el del día que se tragó la peseta, todo un acontecimiento que llamó la atención de los vecinos del barrio, hasta el punto de salir a la calle, a una hora muy avanzada de la noche, para verle desfilar con la moneda defecada (Moix 1998a: 195-196).

Naturalmente, en la escritura autobiográfica, la génesis de la personalidad sintoniza con el problema de la referencialidad, en la medida en que se trata de la propuesta de un escritor de narrarse a sí mismo con el fin de recrear el mundo haciéndolo más comprensible y habitable. La atención al mundo reconocible y compartido es la base de su relato, enfocando las dimensiones ineludibles del ser humano: infancia, adolescencia, juventud, madurez y vejez, redescubriendo los primeros recuerdos,

${ }^{3}$ El sentido estético que alcanza la autorrepresentación como búsqueda de la diferencia es puesto de relieve por Molero de la Iglesia (2012: 167-183). 
la casa, la familia materna y paterna, el colegio, el descubrimiento del sexo, la amistad, los amores, la profesión o la vida familiar. Entre estos tópicos autobiográficos, algunos memorialistas dan prioridad a la etapa de madurez y vejez a la hora de revisar su pasado; Terenci Moix, en cambio, incide de modo exhaustivo en el espacio de la infancia y la adolescencia, como zonas de referencia personal en las que apoyar las tendencias de la persona, la configuración de su polémica personalidad, la disidencia que caracterizó su vida y su obra. La necesidad de autonomía e independencia, el descubrimiento de la sexualidad, el consumo del alcohol, la inestabilidad emocional, el interés por la cultura y los viajes, el sentimiento de fracaso, la rebeldía, la ambición desmedida, la crisis de identidad, el inconformismo, la inseguridad en sí mismo y el narcisismo son rasgos asociados a la persona que el lector verifica en sus memorias porque son también los que estructuran el personaje literario ${ }^{4}$. La voz narradora en primera persona instrumentaliza dichas facetas para componer una imagen comprensible y cercana, comprometiendo la complicidad del receptor, tanto en las causas de su yo-diferente como en las consecuencias para ese adolescente que tan pronto tomó las riendas de su propio destino (Moix 1998b: 231).

A este objetivo sirve el relato histórico sobre la iniciación de Ramón al tabaco, al consumo del alcohol y al despertar de su sexualidad (Moix 1998a: 40), pues el cambio físico y psicológico que experimenta, objeto de curiosidad, de miedo y de sufrimiento, también lo es de importantes interrogantes y angustias que le llevan a meditar sobre su propia esencia personal y ubicación social para declarar públicamente su homosexualidad.

Pero el valor de esta revelación no reside tanto en la asunción responsable de su inclinación sexual, sino en la reflexión sobre una circunstancia que la persona experimenta como fuente de pudor y de dolor. Al pudor se sobrepone con el léxico y la expresión, incidiendo en los detalles de sus múltiples relaciones sexuales y abundando en el lenguaje escatológico y obsceno que elige para nombrarlo. Ambas dimensiones son claves como formadoras del sujeto en Moix, instrumentos que le sirven para romper con los códigos ético-sociales de lo que es y no es decible, de lo que debe quedar en el ámbito de la intimidad. Pero nada mejor que la fórmula testimonial para infiltrar al lector el sufrimiento de un adolescente, que debe comprender e interpretar su interior sin consejos ni apoyo de formadores, desarrollando la falta de confianza en sí mismo, la experiencia de la continua frustración y la consecuente inestabilidad emocional. En el terreno de la conquista amorosa se manifiesta con absoluta naturalidad, apelando al inevitable sufrimiento adolescente por el desamor, si bien enmarcado en la cultivada pose romántica del espíritu atormentado, llorando por la ruptura, emborrachándose o rapándose la cabeza para llamar la atención del amado (Moix 1998c: 590-592).

También su experiencia viajera será tratada como materia formadora de la persona. No puede ser de otra manera para un joven que busca su desarrollo vital,

\footnotetext{
${ }^{4}$ Una muestra de los problemas que conoce el adolescente se encuentra en Menéndez Benavente (2011).
} 
emocional e intelectual fuera de la asfixia de la dictadura política. Terenci Moix explora al personaje Ramón como un adolescente viajero extravertido, que se integró de lleno en la cultura de otros países (Francia, Italia, Inglaterra) aprendiendo su lengua. Por eso, marca su superioridad frente al entorno, por hacer valer su saber con cierta pedantería y esnobismo. A la idea de cosmopolitismo y experiencia mundana que tiene Moix responde ese personaje de trato fácil y fluido que, sin embargo, tiene problemas de índole sentimental, superando el deseo a los logros conseguidos; la frustración por el fracaso de intimar con ciertos amigos es una de las situaciones personales que se repite, hundiéndole en una tristeza y abandono físico que le llevan a refugiarse en la cultura, su terapia personal. Dedicará buena parte de su tiempo a leer, escribir y ver cine, invirtiendo esfuerzo en esa formación autodidacta que caracteriza la figura del escritor.

Será esta situación crítica, es decir, la de la decepción en el terreno de la conquista amorosa, la que le obligue a volver a oponerse y de manera visceral a las teorías de la Iglesia católica sobre la sexualidad, evocando con mordaz ironía su pasado infantil, en la escuela nacional católica, en la que los curas censuraban la relación de amistad y amor entre alumnos del mismo sexo (Moix 1998a: 217). Su testimonio pone énfasis en su anticlericalismo, su deseo manifiesto de ajustar cuentas pendientes con los curas para sentirse bien consigo mismo, dotar de sentido su propia leyenda y, por fin, defenderse o justificarse ante los que le reprochan ser excesivamente provocador. Pese a la evidente manipulación de la materia personal, sus memorias reflejan la esencia de la persona en el personaje; no importa el grado de fidelidad histórica que tiene el autorretrato psicológico y sentimental cuando a través de él comprendemos la experiencia personal:

Yo no había sido un niño normal; después fui un adolescente raro; ahora me estaba adiestrando para ser un joven herético, pero ni siquiera me parecía a los que comulgaban en mi herejía. No era como los demás en ningún campo. No estaba previsto en ningún sitio (Moix 1998c: 11).

Fiel a su propia disciplina, y sobre la base de sus constantes autoalusiones, cultiva el sentimiento trágico de la vida, una vida problemática sobre la que reflexiona, ironiza ${ }^{5}$ y se lamenta pidiendo la comprensión del lector, removiendo su estado de ánimo, provocando su implicación en las vivencias del personaje, haciendo que tenga la sensación de que se reconozca en las emociones y los hechos. Tal maniobra tiene el efecto del acto confesional, en el que el yo se confiesa a un tú para liberarse de la angustia existencial. Sin duda, como los componentes negativos se imponen sobre los demás en su periplo vital, todo redunda en el pesimismo o en la ruina personal, pilar de su narrativa. El relato homodiegético, que sacraliza todo lo negativo del individuo, se sustenta en este autor, en este sentido, tras declararse, a pesar de sus logros literarios, «deshecho y sin ganas de vivir» (Moix 1998c: 625), hundido por

5 Cf. Fone (2011: 131-144). 
una agitada vida sentimental, la lucha por la supervivencia, la enfermedad y muerte de familiares y amigos, la soledad y el paro. Como ocurriría en los modelos miméticos de la narración histórica, biográfica, así como en los modelos de la narración picaresca, muestra, en definitiva, una voluntad clara de hacer prevalecer el yo sobre las circunstancias históricas importantes en la escritura memorialística, dando relevancia al sujeto ante las circunstancias de su vida. Es en este sentido en el que se ha de entender a Bruss (1991: 72), cuando dice que "hablar en primera persona es identificarse a uno mismo como la fuente principal de la comunicación y hacer de este asunto un asunto central en esa comunicación». De ahí el carácter autobiográfico del relato, fortalecido por el uso de los adjetivos posesivos de la esfera de la primera persona, tanto del singular como del plural, que salpican las páginas de sus memorias. Dicha implicación de la intimidad del yo, que pretende dar más verosimilitud a lo contado, hace que lo que el lector ve en primer plano sea al personaje, quedando un tanto desenfocado su entorno. En cualquier caso, el yo terenciano no es un yo diplomático o ambiguo que se niega a responsabilizarse de los hechos experimentados en su infancia y adolescencia; más bien al contrario, supone autorreferencias conscientes y narcisistas. En fin, la primera persona ${ }^{6}$ del singular en conexión con los posesivos correspondientes, a los que Moix recurre para narrarse, para observarse y para reconocer su propio rostro, pero también para luchar contra las tentaciones de la mentira y las flaquezas de la memoria, dotan el discurso de un carácter básicamente autobiográfico.

Así pues, en su deseo de dar forma a la memoria construyendo una imagen textual de acuerdo con su propia conciencia, el memorialista catalán apelaría a la primera persona del singular para distanciarse del golpe psicológico que supuso su homosexualidad, plasmar las duras condiciones de los viajes realizados por España, como alegato de su exilio, o denunciar la censura que pesaba sobre su obra. Situaciones personales, sin duda, pero que atañen en diferentes grados y dimensiones al residente en España. Así es como este yo individual encontrará receptores solidarios en la lectura, convirtiéndose en un yo colectivo.

El juego de la memoria, al que Moix somete al yo literario, en su constante búsqueda ontológica, reconstruyendo los hechos que han marcado su periplo vital, insistiendo en algunos de ellos que acaban por constituirse en estructura básica de

${ }^{6}$ En esta línea trabaja Lejeune (1994: 56-57), para quien la primera persona se define por la articulación de dos niveles: «1. Referencia: los pronombres personales (yo/tú) solo tienen referencia real en el interior del discurso, en el acto mismo de la enunciación. 2. Enunciación: los pronombres personales de primera persona señalan la identidad del sujeto de la enunciación y del sujeto del enunciado». Lejeune (1980: 98) recoge los planteamientos de Benveniste, quien subraya que la primera persona del singular es una forma autobiográfica por excelencia, un yo lírico: «Je est l'individu qui énonce la presente instance de discours contenant l'instance linguistique 'je'». Por su parte, Caballé (1995: 23) arguye que legitima el discurso, evidencia la autorreferencialidad, dispone de todos los secretos de la condición humana y, desde un punto de vista pragmático, además de su naturalidad expresiva, produce un efecto realista de lo narrado, suscitando la adhesión del lector. Sin embargo, tal como recuerdan respectivamente Lejeune (1980: 9), Lecarme y LecarmeTabone (1999: 191), la primera persona es sospechosa para Rimbaud, quien opina que yo es otro, y resulta censurable para Wilde y Proust. 
su escritura, le obliga a objetivarse mediante la tercera persona; sobre todo en el Epilogo en Nunca Jamás (1993), un texto reflexivo y apologético cuyo relato recoge el material biográfico correspondiente a la adolescencia de Ramón. Se configura en esta entrega un personaje autodidacta, consciente de una homosexualidad que si bien le excluye de la «normalidad» le aboca a la perspectiva diversa y creativa de la cultura. En la empresa de buscarse a sí mismo en el relatar de la propia conciencia, hará de la escritura autobiográfica la tabla de salvación personal, reconociéndose desde el principio como un sujeto desgraciado dispuesto a luchar por forjarse una vida acorde con sus inquietudes y convicciones.

Será el trayecto vital que media entre el descubrimiento y la superación el que requiera un modo discursivo adecuado a la ajenidad. Molero de la Iglesia (2000) pone de relieve la tensión existente entre el sujeto que narra y el personaje que fue, textualizada mediante el recurso de las figuras de narración; entre ellas, la elección de la tercera persona conviene a un narrador que desea evidenciar el distanciamiento psicológico con la comprensión del mundo que tiene el personaje, lo que no impide un acercamiento afectivo hacia él mismo mediante comentarios de comprensión y argumentación a favor de sus conductas. En las memorias de Moix, el uso de la tercera persona escenifica el cambio que Ramón va experimentando, atribuyéndole la capacidad de meditar sobre su situación en el mundo y la necesidad de buscar fórmulas para sobrevivir de acuerdo a sus inquietudes y personalidad. Es evidente la presentación orgullosa que hace en el balance de su vida, pero también del adolescente que fue y cómo encaró la circunstancia personal en una sociedad de incomprensión.

El significado habitual de la narración heterodiegética en la escritura personal tiene que ver con la objetivación y la observación distanciada, cuando no el extrańamiento, de la conciencia del otro que se fue alguna vez. En relación con la observación distanciada, la voz del autor-narrador-personaje que organiza el discurso se propone distanciarse de todos los estereotipos y estragos sufridos en plena adolescencia por el mero hecho de ser homosexual. De este modo, la tercera persona aparece en Moix como una fórmula de extrańamiento para oponerse a una sociedad cerrada e intolerante, por lo que May (1982: 75) ve en dicha figura de la narración una actitud histórica ante los hechos contados. Básicamente, la tercera persona no marca la distancia entre el presente y el pasado de Moix, es decir, que cuesta observar un desconocimiento del narrador actual frente al yo del pasado, justificado por el hecho de que el adulto Terenci Moix nunca se distanció de Ramón, como sujeto infantil y sujeto adolescente. Y es que objetivamente, viene a entenderse que nunca cambió su filosofía de vida, la de ser siempre Peter Pan, y que si en algunos memorialistas la tercera persona se contempla como una forma de humildad, para él representa, sin embargo, un inmenso orgullo por permitirle destacar y reafirmarse en la creencia de sus valores de siempre. Entre otros, la lucha por la libertad, que disfruta en París, maravillándose ante todo lo prohibido en España; su compromiso por la formación intelectual devorando libros en la librería Shakespeare and Company, asistiendo a clases de la Alliance Française, a múltiples conferencias, a cursos en la Sorbonne, viendo películas, viajando, fumando y practicando el sexo de forma compulsiva. En su relación con la cultura de la libertad y una juventud transgresora y 
revolucionaria, «Ramón Moix Meseguer descubrió su juventud» (Moix 1998b: 599) $y$ un deseo profundo de cambiar el mundo.

Pero no superará el sentimiento de fracaso y seguirá reconociéndose como un joven triste y solitario, marcado por las carencias afectivas, y también económicas, ya que para sobrevivir tanto en París como en Chelsea tendrá que desempeñar trabajos relegados a los inmigrantes. También esta circunstancia incidirá en la formación de una persona que experimentó la vida de los desplazados que luchan por sobrevivir en tierras ajenas. En resumen, ofrece en el relato de estos años un balance catastrófico de su vida, haciendo uso del narrador heterodiegético buscando poder realizar un análisis distanciado del personaje. Opina Lejeune (1994: 53 y 102) que es una fórmula que siembra duda sobre el enunciado, por lo que será el lector quien deba interpretarlo para dotarlo de sentido. Como marca de la distancia entre el presente de la escritura y el pasado de los recuerdos, es decir, entre la vida vivida y lo contado en la escritura, lo que se cuenta no es veraz, tampoco auténtico, ya que por ser hechos seleccionados de manera interesada para maquillar la imagen del autor -también por el capricho de la memoria-, resulta difícil contarlos siguiendo un orden estrictamente cronológico. En este sentido, es evidente la diferencia entre la vida real y la vida psicológica, dado que, por la autocensura, el subconsciente, la asociación de ideas, de recuerdos y de imágenes, los detalles se pierden; también existen conexiones difíciles de restaurar en el acto mismo de la escritura, idea en la que también se apoyan las teorías filosóficas y deconstruccionistas ${ }^{7}$ para ratificar la crisis de la identidad autobiográfica. Sin embargo, la intención de Moix es escribir unas memorias que reflejen su propia historia y evolución personal, estimulada su escritura por el disfrute estético de reconocerse y afianzarlo públicamente.

Pero la escritura autobiográfica no se limita al recuerdo y el relato de lo vivido, desde el momento en que el narrador se convierte en juez y evaluador, filtrando la actividad y la conciencia del personaje en relación con una ideología o postura vital. Dicho ejercicio de observación se aplica con mayor énfasis al relato del aprendizaje, haciéndose evidente en Extraño en el paraiso, cuando el discurso impersonal refleja la especulación del sujeto enunciador:

¿Qué se es a los veinte años? Niño, hombre, adolescente, todo a la vez como la propia década. Se es un desconcertado y un peregrino. Un extraño en todos los paraísos y un eterno viajero que todavía ha de averiguar adónde conducen las rutas que empezaron al este del edén. Un cinéfilo, un literato, un enamorado; un masturbador, en resumen. Y el tiempo es siempre el del onanismo (Moix1998c: 10).

La construcción de la imagen personal debe mucho al modo reflexivo, que prevalece en sus textos, combinando el relato de la memoria y la exposición comentativa para argumentar tanto las acciones del personaje como su personalidad, erigiéndose en moralizador o doliéndose por las dificultades de la vida, pero siempre

\footnotetext{
${ }^{7}$ En esta línea se sitúan De Man (1991), Catelli (1991) y Jay (1993), entre otros.
} 
aportando una visión evaluadora ${ }^{8}$ de los hechos y la evolución del personaje. Tal maniobra, con la intención de acercar al lector a su peculiar trayectoria buscando la necesaria implicación, para dar sentido a los problemas que atormentaban al personaje en la adolescencia, su necesidad de crecer culturalmente y de compensar el desarraigo con la superación intelectual. En suma, busca la redención estética de un personaje que se define por una problemática historia sentimental y las consecuentes situaciones depresivas o sentimientos de ruina total'.

Será, precisamente, su lenguaje unívoco y denotativo lo que desnude esa esencia personal, ese efecto de autenticidad que hizo de Moix el icono de muchos adolescentes gais en una España franquista, que se opone de manera radical a la homosexualidad, considerada como delito y castigada por la ley. Desde la perspectiva de la voz narradora, la imagen de un adolescente hambriento de libertad, incomprendido, desgraciado, atrevido, rebelde, hundido y desprotegido apunta a una reflexión de alcance universal, plasmando problemas en los que puede reconocerse, con las variantes que sea, cualquier ser humano. En su ejercicio de autoescritura, el escritor se deja llevar por el placer de la evocación, el individualismo, el exceso de protagonismo personal y el convencimiento de que la voluntad de una comunidad de gente puede romper con la intransigencia y la marginalidad social; percepción que estimuló su lucha hasta el final de sus días, produciéndole un enorme sentimiento de plenitud y realización. Sin duda, cabe hablar de su deseo de exhibir la conciencia y proyectarla en el discurso, con el fin de provocar una reacción social, desembocando en lo que Castilla del Pino (2004: 19-26) denomina el eco autobiográfico, pero su objetivo es generalizar su caso y el significado de su discurso, preñándolo de una dimensión universal.

Ya Diltley dejó establecida la conexión entre la autobiografía y la historia, sosteniendo que no es solo una expresión individual, sino también producto de una conciencia histórica, tesis compartida por Batjín (1989), Weintraub (1993), Loureiro (1993) y Romera Castillo (2006). La relación entre texto e historia, siguiendo el esquema de división de la autobiografía propuesto por Gusdorf (1991a), pertenece a la etapa de bios, pues en dicho nivel, la sinceridad y la exactitud resultan claves para la interpretación histórica. Sobre dicha base y por la imposibilidad de escribir su pasado ignorando su entorno, también el uso del nosotros señala a una pluralidad de ámbitos en la escritura memorialística moixiana.

${ }^{8}$ Es en este sentido en el que se ha de entender a Gusdorf (1991b: 14-15) cuando sostiene que «la autobiografía responde a la inquietud más o menos angustiada del hombre que envejece y que se pregunta si su vida no ha sido vivida en vano, malgastada al azar de los encuentros, y si su saldo final es un fracaso». Añade que «la narración nos aporta el testimonio de un hombre sobre sí mismo, el debate de una existencia que dialoga con ella misma, a la búsqueda de su fidelidad más íntima».

${ }^{9}$ Esta patética y dolorosa historia sentimental, que experimenta Moix a través de los viajes, las tertulias, las cartas de amor y desamor, también puede verse en una de las novelas documentales de Molina Foix (2016). 
El más genérico coincide con la implicación del sujeto cultural ${ }^{10}$ que conlleva siempre la representación del sujeto individual, por lo que afecta al receptor de un discurso que busca la identificación y apela al ser social. En este sentido, Moix remite la construcción del propio personaje a su desenvolvimiento en los entornos siempre reconocibles de la familia, los amigos, la cultura, el servicio militar, las fiestas, el cine del fin de semana u otros muchos lugares comunes para el receptor que comparte la cultura de un tiempo y un lugar. De este modo, la miseria que conoce España tras la contienda civil, tan evidente en una precaria red de carreteras que imponía largos y penosos viajes, apela a ese nosotros ${ }^{11}$ en el relato del viaje de Barcelona a Madrid, del que recuerda ir «ateridos de frío y con los huevos machacados a causa de la incomodidad de los bancos de madera" (Moix 1998b: 397-398).

Este nosotros, que se explica en cuanto conciencia colectiva que identifica determinado grupo social, justifica el efecto de interacción propio del discurso autobiográfico y el memorialista, definido por apoyarse en el reconocimiento del contexto, por parte del lector, al hacerle partícipe de una experiencia que, sin embargo, es personal. El mismo nosotros emplea para referirse a toda una generación de adolescentes de dieciocho años que lloran por la muerte de Marilyn Monroe, una actriz del cine americano, a la que admiraban por su erotismo, belleza y sensibilidad. Con dicha pérdida, tan enorme para ellos, caen en la desolación total, al verse frustradas sus aspiraciones (Moix 1998c: 27).

Pero hay un referente no tan común del nosotros que acota una ideología y una forma de vida que incluye a Ramón en la revolución juvenil de la Rive Gauche, atribuyéndole una identidad particularizada en el grupo de españoles disidentes, «exiliados» en París y a los que les unía el ansia de "pertenecer a esa patria utópica», y la «intensa curiosidad por las cosas que pudiera proponernos la nueva década» (Moix 1998c: 82-83). En el mismo ámbito, se puede valorar el nosotros de los desarraigados y los desplazados que buscan sobrevivir en un país ajeno, o el referente del emigrante, en Londres, marcado por la inestabilidad, la vida provisional y precaria, la búsqueda continua de un medio para sobrevivir.

Y aún más restrictivo podría ser ese nosotros que alude al colectivo que reivindica la bandera de la homosexualidad, faceta personal que constituye el rasgo diferencial del personaje y el componente más explotado y desarrollado en la escritura de la memoria personal. Su obsesión por llevar a cabo un desnudo psicológico y moral lleva a Moix (1998c: 439) a profundizar en la sociedad española del franquismo - periodo en el que el homosexual sufre todo tipo de vejaciones, dado que el Estado, apoyado por el Ejército y la Falange, le considera un enfermo o un delincuente que se tiene que aislar para curar y reeducar socialmente, poniendo en mar-

10 Cf. Cros (1981).

${ }_{11}$ A este respecto, Gusdorf (1991b: 10) opina que «durante la mayor parte de la historia de la humanidad, el individuo no ve su existencia fuera de los demás, sino con los otros, en una existencia solidaria cuyos ritmos se imponen globalmente a la comunidad». 
cha decretos y leyes, como la Ley de Peligrosidad y Rehabilitación Social para castigarle y mandarle a la cárcel-, plasmando el clima de intolerancia y persecución.

La referencia al episodio personal cumple aquí una función testimonial, descendiendo el relator a un tono anecdótico que, sin embargo, contrasta con el tono irónico y airado que inspiran los hechos a quien reflexiona desde la escritura de la memoria. Pero su móvil discursivo no acaba en la indignación individual, sino que quiere proyectarse en la modificación de la realidad social, buscando influir en el cambio de una mentalidad que evoluciona a marchas forzadas tras la muerte de Franco (Moix 1998c: 255), proponiéndose entrelazar su memoria con la memoria colectiva e histórica, sumar voluntades con el fin de solidarizarse y denunciar la persecución sufrida por todo el colectivo gay ${ }^{12}$. En tal sentido, no hay duda de que sus memorias han influido considerablemente en la visión del público lector, respecto a la realidad social de la homosexualidad, como también colaboró la imagen que cultivó desde otros medios, como la televisión.

La combinación de figuras para construir el personaje literario contempla la propia imagen en el recuento de lo vivido, lo que conlleva representar el dinamismo psicosocial del individuo, la evolución que hace que lo que Ricoeur (1990) denomina identidad narrativa no sea una foto fija, una realidad estática, sino un sistema sometido a constante transformación y evolución, implicando la colaboración del lector autobiográfico ${ }^{13}$, ya que este debe interpretar la función que desempeña cada figura en la construcción textual; al respecto, Lejeune (1994) aconseja no confundir los problemas gramaticales de la persona con los de la identidad. En relación con estas consideraciones, el grado cero de dichas figuras en las memorias moixianas remite a la incidencia del temprano deseo de emancipación, que embargaría a Ramón desde la niñez hasta la adolescencia, manteniéndose en la juventud y la madurez.

Dicho principio vital se convierte en la personal forma de estar en el mundo $y$, en consecuencia, de entender la expresión estética y el arte. Ante todo y sobre todo, la expresión de la libertad será el pilar básico de su vida hasta la muerte, extremando su manifestación hasta la exhibición, para contrarrestar la ira por la repre-

${ }^{12}$ La autobiografía como acto individual y solidario también puede rastrearse en los escritores Sand, Simone de Beauvoir, Montaigne y Perec (Lecarme y Lecarme-Tabone, 1999). En esta línea trabaja también Gusdorf (1998b: 10).

${ }_{13}$ A tal propósito, sostiene Lejeune (1980: 37) que «l'emploi de ce procédé met en évidence deux choses: d'une part la co-présence dans l'énonciation d'un 'je' (devenu implicite), d'un 'tu', et d'un 'il' (caché sous le 'tu'), renvoyant tous trois au même individu. D'autre part, le caractère double du destinataire: si je me parle en me disant 'tu', je donne en même temps cette énonciation dépliée en spectacle à un tiers, l'éventuel auditeur ou lecteur: celui-ci assiste à un discours qui lui est destiné, même s'il ne lui est plus adressé. L'énonciation s'est théâtralisée: elle n’a pu se déployer ainsi que parce qu'une rampe imaginaire lui garantit son unité et sa relation avec son ultime destinataire. Or cette théâtralisation existe déjà implicitement dans beaucoup de textes autobiographiques en 'je': le lecteur peut aussi bien croire que 'je' lui parle directement ou que 'je' lui montre comment il se parle. En réalité, le destinataire est toujours double, mais selon le choix du pronom, l'un de ses aspects se trouve mis en avant et masque en partie l'autre». 
sión. Las memorias constituyen así la mejor reivindicación de la persona, un campo idóneo para hablar abiertamente de él mismo, de sus obsesiones, devociones, filias y fobias, haciendo literatura de su propia vida, destacando fundamentalmente un lado erótico que nutre la curiosidad y el interés que dicha dimensión despierta en el lector. No podemos obviar las características del contexto social en el que Terenci Moix publica sus memorias, sin duda subversivas, pero enmarcadas en la necesaria exageración reivindicativa que marcó la transición democrática en España, con su apertura a la liberación de las conductas.

Las figuras enunciativas en un texto autobiográfico son siempre estratégicas, ya que responden a los intereses de construcción estética, jugando a favor de la interpretación plural del enunciado. Fernández Prieto (2004) aporta su peculiar visión en su clasificación de textos autobiográficos de orientación testimonial en función de las circunstancias históricas en las que se inscriben (guerra civil, dictadura franquista, miseria, censura, falta de libertad, etc.), y donde incluye las memorias de Terenci Moix para fijarse, sobre todo, en El cine de los sábados:

... el carácter relacional de la identidad, la imposibilidad de ser y de hacerse sin los otros y la conciencia de que el sujeto se constituye dialógicamente, mediante un constante ejercicio de identificación o rechazo de palabras, actitudes y comportamientos ajenos. El yo autobiográfico se presenta fundamentalmente como un yo moral, afectado por los valores dominantes en el entorno familiar y educativo, por las circunstancias sociales y políticas del país, y por los códigos ideológicos impuestos desde el poder, pero dispuesto a cuestionarlos e incluso a romper con ellos (Fernández Prieto 2004: 424).

Si bien Fernández Prieto (2004), retomando a Loureiro $(2000,2016)^{14}$, destaca esta dimensión ética, de compromiso con el otro en la teoría autobiográfica, cabe decir que en algunos memorialistas, la concurrencia de figuras narrativas genera un efecto de polifonía textual, diseñada más para ocultar al personaje que para mostrarle, respondiendo a una especie de teatralización ${ }^{15}$ en el relato autorreferencial, que se correspondería más, según algunos críticos, con los modos de la autoficción ${ }^{16}$. A

${ }_{14}$ Loureiro (2016: 41) entiende que la autobiografía «no es una restauración del pasado sino un acto singular de auto-creación como respuesta, responsabilidad y promesa (de verdad). Como tal, este acto es siempre dialógico, está siempre dirigido al otro, y por lo tanto es siempre intrínsecamente contestable e incompleto».

15 Para Lejeune (1980: 316), hay en «les faits d'expression ‘à la première personne’ ni unité, ni éternité: 'je' passe son temps à être autre, et d'abord autre que ce qu'il était avant...». En la misma dirección, Mathieu-Castellani (1996: 44) argumenta que la «substitution de la troisième personne à la première est parfois aussi la sécrète défense que le sujet invente pour pouvoir dire ce qu'il ne pourrait dire autrement, pour écouter une 'pensée', pour la désavouer à peine avouée. Pour déclarer, comme par le recours à la dénégation, ce qui insiste et dont je souhaite à la fois la représentation et l'effacement».

16 En tal marco, Torres (2013: 2-3) destaca cómo Bonilla, biógrafo de Terenci Moix, en varias ocasiones, "pone en duda la existencia real de algunos personajes que dibuja Moix, como un tal Alexander, o Carlitos - al que Terenci describe como su doble exacto-, y más bien propone que se trata del fruto de las artimañas literarias del biografiado». 
esta idea responde lo que Lejeune llama el tremblé de la mémoire, los escritores Jacques Roubaud, Louis-René des Forêts y Claude Simonel tremblé de l'identité (Lejeune 1998: 40); a lo que Starobinski, apoyándose en la tesis de Maurice Blanchot en Le livre à venir y que recoge Miraux (2005: 18), entiende como estilo autobiográfico o Pozuelo Yvancos (2006: 86) considera como control de la interpretación. En el caso de Terenci Moix, la combinación de figuras enunciativas es igualmente un recurso estético mediante el que representar y definir su propia identidad, contrastando los estados y evoluciones que conforman una personalidad. El efecto formal más notable es la configuración del sujeto desde la pluralidad y la fragmentación, con la que Moix quiere mostrar la transformación del yo; en el plano del contenido es la representación de la complejidad, la conflictividad y la especificidad del personaje lo que domina la voluntad narrativa; objetivo común, sin embargo, a muchos escritores autorreferenciales de la segunda mitad del xx que confirman lo que Lejeune (1998: 15) denomina ilusión de originalidad. Con respecto a esta acción textual reflexiona también Molero de la Iglesia (2012: 173):

El escritor postfreudiano traducirá su percepción de un sujeto múltiple en fenómenos textuales que representen dicha dispersión, abandonando la estructuración lineal que organizaba el relato moderno, para reflejar tanto el entorno inconexo que percibe como su propia diseminación, a través del desorden expresivo.

Efectivamente, las memorias terencianas resultan un manifiesto problemático sobre su sentido ${ }^{17}$ poniendo de relieve una identidad que se construye en el caos y la volubilidad, en su constante proceso de adaptación a un entorno adverso que lo aboca a frecuentes episodios de crisis y angustias existenciales, principalmente motivados por las carencias afectivas y las frustraciones amorosas. Su escritura cautiva por esa labor de contemplarse y analizarse en un espejo de palabras, donde se refleja la imagen que tiene de sí mismo un mitómano que se busca, se cuestiona y se comprende o se justifica constantemente en un discurso confesional ${ }^{18}$ dirigido al público. En este sentido, los textos memorialísticos de Moix constituyen un discurso representativo del Yo actual, en el que subyace la reflexión sobre las teorías modernas del sujeto. Pese a todo, el ejercicio creador que asiste siempre a la escritura del yo aparece muy solapado para el lector ingenuo bajo el relato de la retrospección, básicamente dominado por el narrador en primera persona que siempre consigue confundir la voz del presente con la del pasado, la reflexión de la conciencia que narra con la del sujeto narrado produciendo esa ilusión de referencialidad que denuncia Paul de Man (1991). En fin, el desdoblamiento del neurótico Moix en las

${ }_{17}$ Sobre esta idea de la concepción esencialista de la autobiografía, Mathieu-Castellani (1996: 199) señala que «le jeu des résistances internes qui interdisent l'entière nudité pour préserver la part de secret inaliénable, et qui imposent de faire la confession d'un masque, éclaire le conflit intime entre la revendication de liberté langagière, le désir de mise à nu et la crainte que suscite le déshabillage, voire la terreur qui inspire au sujet le regard du juge, qu'il soit extérieur ou intérieur».

${ }_{18}$ Una muestra de la autobiografía como confesión se encuentra en Zambrano (1988). 
figuras narrativas ${ }^{19}$ es para provocar, rompiendo con la voz autobiográfica tradicional, sirviéndose de otros procedimientos discursivos para llevar a cabo una representación de la esencialidad personal.

A modo de conclusión conviene resaltar que, en sus memorias, Terenci Moix no pretende ni mucho menos contar toda la verdad sobre sí mismo, sino dar sentido a su trayectoria vital, enmarcándola en el proyecto evolutivo de una sociedad. La peculiaridad de este escritor no estriba tanto en la innovación narrativa como en la desinhibición expresiva; pero sobre todo su acción subversiva reside en los contenidos que definen a un inconformista radical, un rebelde con causa en lucha constante contra la opresión moral e intelectual. Moix sobrepone su perspectiva a la visión que impone el pensamiento oficial, radicaliza su lenguaje para luchar contra el discurso radical, legitima su existencia deslegitimando la intransigencia que quiere anular la diversidad social y exhibe su diferencia personal para que se vea reflejado en ella todo aquel que vive doblegado en cualquier ámbito de marginalidad.

Recibido: junio de 2018; ACEPTADO: noviembre de 2018

19 La combinación de las figuras de la enunciación narrativas ha planteado problemas teóricos. May (1982: 77) resalta la relación de ambigüedad que existe entre la persona en el sentido gramatical, psicológico y ontológico de la palabra; Villanueva (1991: 207) habla de puros significantes, por definición, convencionales para un significado sustancial pero problemático, consideración que erige la autobiografía en una literatura polémica y la vida en un cuento o una novela. Desde esta misma visión, Fernández Prieto (2004: 430) opina que dichas «opciones enunciativas y estilísticas se vinculan, claro está, con una imagen del vivir como un ejercicio cotidiano e imprevisible, azaroso y esquivo, y de ahí que el efecto producido sea el de identidades en gran medida inciertas, frágiles, inseguras, que encuentran en el humor y la auto ironía sus asideros existenciales y a las que la literatura proporciona el único territorio seguro, el disfraz protector». 


\section{BIBLIOGRAFÍA}

BAL, Mieke (1998): Teoría de la narrativa. Una introducción a la narratología, Madrid: Cátedra.

Batjín, Mikhail Mikhailovich (1989): Teoría y estética de la novela, Madrid: Taurus.

BRuss, Elisabeth (1991): "Actos literarios», Suplementos Anthropos 29: 62-79.

Caballé, Anna (1995): Narcisos de tinta, Madrid: Megazul-Endymion.

Castilla del Pino, Carlos (2004): «El eco autobiográfico», en Celia Fernández y M.a Ángeles Hermosilla (eds.), Autobiografía en España: un balance, Madrid: Visor Libros, 19-26.

Catelli, Nora (1991): El espacio autobiográfico, Barcelona: Lumen.

Cros, Edmond (1981): Proposition pour une sociocritique. Montpellier: CERS.

Fernández Prieto, Celia (2004): «Enunciación y comunicación en la autobiografía», en Celia FernÁndez y M. ángeles Hermosilla (eds.), Autobiografía en España: un balance, Madrid: Visor Libros, 417-432.

Fone, Thomas (2012): «Ironía en la escritura memorialística de Terenci Moix (El cine de los sábados, El beso de Peter Pan y Extraño en el Paraíso)», Epos xxvir: 131-144.

GonzÁlez Loureiro, Ángel (1993): «Direcciones en la teoría de la autobiografía», en José Romera et alii (eds.), Escritura autobiográfica, Madrid: Visor Libros, 33-46.

GonzÁlez Loureiro, Ángel (2000): The Ethics of Autobiography: Replacing the Subject in Modern Spain, Nashville: Vanderbilt University Press.

GonzÁlez Loureiro, Ángel (2016): Huellas del otro. Ética de la autobiografía en la modernidad espanola. Madrid: Postmetropolis.

Gusdorf, Georges (1991a): Les écritures du moi. Lignes de vie 1, París: Odile Jacob.

Gusdorf, Georges (1991b): «Condiciones y límites de la autobiografía», Suplementos Anthropos 29: 9-18.

JAY, Paul (1993): El ser y el texto, Madrid: Megazul.

Lecarme, Jacques y Liliane Lecarme-Tabone (1999): L'autobiographie, París: Armand Colin.

Lejeune, Philippe (1980): Je est un autre. L'autobiographie, de la littérature aux médias, París: Seuil.

Lejeune, Philippe (1994): El pacto autobiográfico y otros estudios, Madrid: Megazul-Endymion.

Lejeune, Philippe (1998): Pour l'autobiographie, París: Seuil.

Man, Paul de (1991): «La autobiografía como desfiguración», Suplementos Anthropos29: 113-118.

Mathieu-Castellani, Gisèle (1996): La scène judiciaire de l'autobiographie, París: PUF.

MaY, Georges (1982): La autobiografía, México: Fondo de Cultura Económica.

Menéndez Benavente, Isabel (2011): «Crisis de adolescencia»: http://www.psicopedagogia.com/ crisis-adolescencia.

Miraux, Jean-Philippe (2005): La autobiografía. Las escrituras del yo, Buenos Aires: Nueva Visión.

Morx, Terenci (1998a): El cine de los sábados, Barcelona: Planeta.

MoIx, Terenci (1998b): El beso de Peter Pan, Barcelona: Planeta.

Morx, Terenci (1998c): Extraño en el paraíso, Barcelona: Planeta.

Molero de la Iglesia, Alicia (2000): La autoficción en España: Jorge Semprún, Carlos Barral, Luis Goytisolo, Enriqueta Antolin y Antonio Molina, Bern: Peter Lang. 
Molero de la Iglesia, Alicia (2012): «Modelos culturales y estética de la identidad», Rilce 28, 1: 167-183.

Molina Forx, Vicente (2017): El joven sin alma. Novela romántica, Barcelona: Anagrama.

Pozuelo Yvancos, José María (1994): Teoría del lenguaje literario, Madrid: Cátedra.

Pozuelo Yvancos, José María (2006): De la autobiografía. Teoría y estilos, Barcelona: Crítica.

Puertas Moya, Francisco Ernesto (2004): Aproximación semiótica a los rasgos generales de la escritura autobiográfica, Universidad de la Rioja: Servicio de Publicaciones.

Ricoeur, Paul (1990): Soi-même comme un autre, París: Seuil.

Romera Castillo, José (2006): De primera mano. Sobre escritura autobiográfica en España (siglo XX), Madrid: Visor Libros.

Torres, Antonio (2013): «El tiempo es un sueño pop. Vida y obra de Terenci Moix» (reseña), Argusa, vol. II, núm. 7: 1-6.

Villanueva, Darío (1991): «Para una pragmática de la autobiografía», en Antonio Lara Pozuelo (ed.), La autobiografía en lengua española en el siglo veinte, Lausanne: Sociedad Suiza de Estudios Hispánicos: 201-218.

Weintraub, Karl Joachim (1993): La formación de la individualidad. Autobiografía e historia, Madrid: Megazul-Endymion.

Zambrano, María (1988): La confesión: género literario, Madrid: Mondadori. 